\title{
Determination of Agricultural Mechanization Parameters for Western Region of Uttar Pradesh, India
}

\author{
Tarun Kumar Maheshwari* and Ashok Tripathi
}

Farm Machinery and Power Engineering, VSAET, Sam Higginbottom University of Agriculture, Technology and Sciences (SHUATS), Allahabad-211 007, UP, India

*Corresponding author:

\section{A B S T R A C T}

\section{Keywords}

\section{Mechanization} index, Farm power, Degree of mechanization, Cropping intensity, Human energy, Mechanical energy, Total energy

Article Info

Accepted:

04 August 2019

Available Online:

10 September 2019
According to 2011 census, the population of the UP was about 200 million, which covered about $16.50 \%$ of Indian total population and have about $6.9 \%$ of total area of the country. The state is also divided into 9 agro-climatic zones. The western region of Uttar Pradesh consists of four agro-climatic zones and has 26 districts. Out of 26 districts 5 districts were selected for mechanization study in agriculture which helps in improving safety and comfort of the agricultural worker. In India, there is a need to increase the availability of farm power from $2.02 \mathrm{~kW}$ per ha (2016-17) to $4.0 \mathrm{~kW}$ per ha by the end of 2030 to cope up with increasing demand of food grains. The average size of operational holding has declined to 1.08 ha in $2015-16$ as compared to 1.15 in $2010-11$. The farm mechanization indicators and their variability among all agro-climatic zones of western region were studied. The power availability of western plain zone is significantly highest i.e. $36.4 \%$ in comparison to other three western zones of western region in Uttar Pradesh. The mechanization index, power availability, total energy, mechanical energy are highest in western plain zone in comparison to South western semi arid zone, mid western plain zone and Bhabhar and Tarai zone i.e. 0.964, $5.36 \mathrm{~kW} / \mathrm{ha}, 1738.27 \mathrm{kWh} / \mathrm{ha}$, and $1676.74 \mathrm{kWh} / \mathrm{ha}$ respectively but human energy is highest in mid western plain zone i.e. $87.03 \mathrm{kWh} / \mathrm{ha}$ in comparison to other three western zones of western region. The cropping intensity of mid western plain zone district is $196 \%$ which is more than western plain zone as well as other two western zones. The average value of mechanization index, power availability, total energy, mechanical energy, cropping intensity, human energy, annual farmer income, annual input cost, irrigation intensity in western region of Uttar Pradesh are 0.958, 3.98 kW/ha, 1203 kWh/ha, 1132 kWh/ha, $176 \%, 63.73$ kWh/ha, Rs.263538, Rs.45609 and 176 $\%$ respectively.

\section{Introduction}

Indian has 29 states and population of Uttar Pradesh is the largest and second largest in terms area. As per 2011 census, the population of the UP was about 200 million, which covered about $16.50 \%$ of Indian total population and have about $6.9 \%$ of total area of the country. As per census 2011, about 77.7 $\%$ people still stayed in rural areas after that 
about $22.3 \%$ in urban areas in the state. The rural population covered in Uttar Pradesh was greater than national rural situation i.e. 68.84 percent as per 2011 census. The total workers population in UP was 39338 thousand, out of which cultivators considered $46.98 \%$ followed by $32.56 \%, 15.14 \%$ and $5.32 \%$ of workers engaged in other services, agricultural labors and workers of industries respectively. The gross area of the Uttar Pradesh is 24.2 million hectare, out of which 16.68 million hectare is the net sown area. In Uttar Pradesh, the cropping intensity was about 153 percent as per 2011 census. The small and marginal farmers community is dominated in UP. The average size holding per farmer was only 0.83 ha. The average size per marginal farmer was about 0.40 hectare. The net sown area of Uttar Pradesh was calculated i.e. 11 percent of total area of India, which is approximately $20 \%$ of the total food grain yield of the nation and contributes more than about 41 million tonnes of total food grain. The state is covered by four regions i.e. eastern, western, central and bundelkhand. In Uttar Pradesh state have 75 districts, 327 tehsils, 822 blocks and 107452 villages at present. According to agro-climatic zone, the western region of Uttar Pradesh consists of 4-parts i.e. western Plain Zone, mid western plain zone, south western semi arid zone and bhabhar and tarai zone. The main crop grown of this zone is wheat which covers more than $25 \%$ GCA, medium crops grown are rice and sugarcane, which covers 10 to $25 \%$ of GCA and low crop grown are maize and mustard.

The western plain zone of Uttar Pradesh has 9districts i.e. Ghaziabad, Muzaffarnagar, Meerut, Saharanpur, Baghpat, Gbnagar, Shambli, Hapur and Bulandshar. The production of food grain is about $31.53 \mathrm{q} / \mathrm{ha}$. The soil of this zone is alluvial, ph- normal to alkaline and organic matter minimum to medium quantity. This region has the highest land productivity in the State. The cultivated area is about $70 \%$ land is under agriculture and another 5\% land is under forest cover $76 \%$ of the net sown area is irrigated. Tube wells are the predominant source of irrigation. The zone receives, on an average $907 \mathrm{~mm}$ rainfall, the climate is dry sub-humid to semi-arid and the soil is loam to sandy loam.

This south western semi arid zone of UP covers 8-districts i.e. Agra, Aligarh, Etah, Firozabad, Hathras, Mainpuri, Mathura and Kasanganj. In spite of a relatively high proportion of arable and irrigated cropped area, land productivity in the southwestern plains of Uttar Pradesh is low. This is largely on account of cultivation of low value crops principally wheat and bajra. The production of food grains is $27.5 \mathrm{q} / \mathrm{ha}$. The cultivated area of this zone is 22 lakh hectares. The climate is semi-arid and the soil type is alluvium calcareous clay. The region receives about 721 $\mathrm{mm}$ of rainfall. More than $74 \%$ of the net sown area is irrigated and over $69 \%$ land is cultivated.

This mid western plain zone includes 6districts i.e. Badaun, Bareilly, Moradabad Sambhal, JP Nagar and Shahjahanpur districts. The average rainfall of this zone is $103 \mathrm{~cm}$. The average food grain is $25.17 \mathrm{q} / \mathrm{ha}$. It covers 30.36 lakh ha cultivated area. The soil of this zone is mostly alluvial, ph normal to slightly alkaline and organic matter in medium quantity. The irrigated area of this zone is 83.21 per cent only. The variation in temperature is from 4.5 to 45.4 degree Celsius

The bhabhar and tarai zone includes three districts i.e. Bijnor, Pilibhit and Rampur. The average rainfall of this zone is $140 \mathrm{~cm}$. The average food grain production in the zone is $25.07 \mathrm{q} / \mathrm{ha}$. This zone has minimum to medium in alluvial phosphorous medium to high in potassium and organic matter in high quantity. The irrigated area of this zone is 
$73.29 \%$ only. The variation of temperature is from 5.5 to 38.4 degree Celsius.

In modern era, agricultural mechanization draws a major controversy that it is considered as the application of mechanical power technology, particularly tractors. However, three main levels of mechanization technologies need consideration: human power, animal power and mechanical power technologies, with varying degrees of sophistication within each level (Rijk, 1989), on the basis of capacity to do work, costs, and precision and effectiveness (Morris, 1985). Agricultural mechanization technology further varies from location to location and crop to crop. Thus the quality of inputs of mechanization, and consequently land and labor productivity may differ considerably (Gifford and Rijk, 1980). So, mechanization planning requires the quantification of level of mechanization for each crop production. Several authors developed different methods to quantify the level of mechanization based on power or energy availability, and its impact in agricultural and labor productivity.

Zangeneh et al., (2010) defined Mechanization Index (MI) and Level of Mechanization (LOM), to characterize farming system of potato in the Hamadan province of Iran. These indicators are defined mathematically as equations (1) and (2) respectively. The MI elaborated here is an expression of the deviation of the actual amount of motorized farm work from the normal values at the regional level.

$\mathrm{MI}=\frac{1}{\mathrm{n}} \sum_{\mathrm{i}=1}^{\mathrm{n}} \frac{\mathrm{M}_{\mathrm{e}(\mathrm{i})}}{\mathrm{M}_{\mathrm{av}}} * \frac{\mathrm{L}_{\mathrm{i}}}{\mathrm{TL}_{\mathrm{i}}} \ldots$ (1)

Where,

$\mathrm{MI}=$ Mechanization Index for the production unit ' $\mathrm{a}$ ', $\mathrm{M}_{\mathrm{e}(\mathrm{i})}=$ Overall input energy due to machinery in the production unit 'a', $\mathrm{M}_{\mathrm{av}}=$ Regional-average energy due to machinery, $\mathrm{L}_{\mathrm{i}}$
$=$ Land area cultivated in the production unit 'a', $T L_{i}=$ Total farm land ownership of production unit `a', $\mathrm{n}=$ Number of farms.

The MI index, proposed by Andrade and Jenkins, 2003 is an indication of the amount of machinery a given farmer uses for farm work compared with the average in the region. The second term in Equation (1) includes a ratio between the land area cultivated with wheat crop and the total land ownership. This term was introduced because it reflects the importance of land demand for cultivation. The LOM index is based on the premise that a mechanized farmer is the one that finds a way to utilize amounts of mechanical energy that are higher than the typical values using locally available technology.

$\mathrm{LOM}=\sum_{\mathrm{i}=1}^{\mathrm{n}} \frac{\mathrm{P}_{\mathrm{i}} * \eta}{\mathrm{L}_{\mathrm{i}}} \cdots(2)$

Where, $\mathrm{LOM}=$ level of mechanization, $\mathrm{P}_{\mathrm{i}}=$ power of tractors, $\eta=$ correction factor for utilized power (0.75).

Field capacity was multiplied by rated power so the quantification of energy expenditure was made in work units $(\mathrm{kWh})$.

The regional normal will be obtained after compiling a full dataset of all respondents and then it would be defined the mode for the number of passes for each operation as well as the mode in tractor size and field capacity.

The level of mechanization is calculated by the following formula (Almasi et al., 2000).

Mechanization

$(\mathrm{hp} / \mathrm{ha})=\frac{\text { Total Power }}{\text { Cultivated Area }} \cdots$

The Total power of existing tractors $(\mathrm{hp})=$ Average nominal power of one tractor $\mathrm{x}$ Number of working tractors. 
Total real power of tractors $=$ Total power of existing tractors $\mathrm{x}$ Conversion coefficient (0.75).

Animal energy $(\mathrm{hp}-\mathrm{h})=$ Total existing animal power x Annual functional hours.

Annual functional hours $=$ Number of functional days $\mathrm{x}$ Mean functional hours during a day.

Total existing animal power $(\mathrm{hp})=$ Produced power of animal x Number of animals.

Human energy $(\mathrm{hp}-\mathrm{h})=$ Total exiting human power $\mathrm{x}$ annual functional hours.

Annul functional hours $=$ Number of functional days x Mean functional hours during a day. Total existing human power $(\mathrm{hp})=$ Produced power of human $x$ Number of humans.

\section{Materials and Methods}

After selection of variables, a questionnaire was prepared to collect primary data from each agro-climatic zone of Western region. The selected district from each agro-climatic zone of western region was, Saharanpur from western plain zone, Firozabad and Etah from south western semi-arid zone, Badaun from mid western plain zone and Pilibhit from bhabhar and tarai Zone in western region of Uttar Pradesh. A stratified multistage sampling design was applied considering district and village as strata.

The villages were selected from five mentioned districts from western agro-climatic zones in western region of Uttar Pradesh using random sampling and 5 districts out of 26 districts of western region were taken for the study. Then from each district, 5 villages and then from each villages, 10 farmers were selected using random sampling. Primary data were collected from 200 farmers from 20 villages of 5 districts i.e. 40 farmers from each district. As mechanization is a multidimensional concept, thus the following indices were evaluated to study the mechanization status in target region. To study the mechanization status of five districts of western region of Uttar Pradesh The many variables were selected based on requirements to estimate degree of mechanization, level of mechanization (power availability), mechanization index, cropping intensity, irrigation intensity, input cost and farmers Income. The following variables were selected:

\section{Degree of mechanization (MD)}

It is one of the quantitative measure of mechanization, by which the degree of mechanization of different operations in a cropping system like land preparation, sowing, weeding, irrigation, spraying, harvesting, threshing, transportation of agri-cultural produce and etc. can be assessed. It is the ratio of mechanization area accomplished to the area to be mechanized (Almasi et al., 2000).

The degree of mechanization of particular implements used in a particular agricultural operation can be given as:

Degree of Mechanization =Mechanized area/Area to be mechanized. ...(4)

In other words, the degree of mechanization can be used to evaluate the extent of different agricultural operations performed using machinery or improved implements to the operations performed by humans, animals or traditional implement i.e. Area under bullocks, cultivator, power tiller, disc plough, M B plough, indigenous plough, seed cum fertilizer drill, diesel engine, electric pump, sprinkler, dripper, sprayer (manually operated), sprayer (tractor operated), manual harvesting, thresher and combine harvester. 


\section{Level of mechanization (power availability)}

Farm power is an essential input in agricultural production system to operate different types of equipment for timely field completion of agricultural works to increase productivity and maintain sustainability of farm. The mobile power is used for different field jobs like land preparation, sowing, weeding, spraying, and harvesting etc., whereas stationary power is used for lifting water, operating irrigation equipment, threshing, cleaning and grading of agricultural produce. The main sources of mobile power are human, draught animal, tractors, power tiller and self-propelled machines (combines, dozers, reapers, sprayers and etc.) where as the source of stationary power is oil engines and electric motors. In this study, power availability was also evaluated for western region of Uttar Pradesh. The main sources of mobile power were human, draught animal, tractors and combines whereas the sources of stationary power were oil engines, electric motors and threshers in the western region. The power availability was evaluated using formula given by Equation 5 .

Power availability $(\mathrm{hp} / \mathrm{ha})=$ Total Power/Net Cultivated Area...(5)

Where, Total power $=$ Total mobile power + Total stationary power
Net Cultivated Area $=$ Net Cultivated Area of Target Region Villages wise number of tractor, combine harvester, bullocks, agricultural workers, power tiller, diesel engines and electric pump.

\section{Results and Discussion}

The graphical representation of variation of mechanization index, power availability, degree of Mechanization, cropping intensity, annual farmers income, annual input cost, irrigation intensity, human energy, mechanical energy and total energy for western region of four agro climatic zones i.e. western plain zone, south western semi arid zone, mid western plain zone and Bhabhar and Tarai zone are shown in figure from 1 to 10 (Table $1)$.

The farm mechanization indicators and their variability among different agro-climatic zones of western region were studied. It can be seen that western plain zone is more mechanized in terms of mechanization index and farm power availability and South western semi arid zone is least mechanized. From the graphs, it is also clear that south western semi arid zone and mid western plain zone is almost same mechanized as per mechanization index and farm power point of view. The farm power value in western plain zone is $36.4 \%$ more than south western semi arid zone.

Table.1 Mechanization Status parameters of Western region in Uttar Pradesh

\begin{tabular}{|l|l|l|}
\hline Sl. No. & Mechanization status parameters & Average Values \\
\hline 1. & Mechanization Index & 0.958 \\
\hline 2. & Farm Power (kW/ha) & 3.98 \\
\hline 3. & Cropping Intensity (\%) & 176 \\
\hline 4. & Irrigation Intensity (\%) & 176 \\
\hline 5. & Annual Farmers Income (Rs) & 263538 \\
\hline 6. & Input cost per year (Rs) & 45609 \\
\hline 7. & Human Energy (kWh/ha) & 63.73 \\
\hline 8. & Mechanical Energy (kWh/ha) & 1132 \\
\hline 9. & Total Energy (kWh/ha) & 1203 \\
\hline
\end{tabular}


Table.2 Degree of mechanization of different farm implements of Western region of UP

\begin{tabular}{|l|l|}
\hline Degree of mechanization & Average values \\
\hline Cultivator & 0.709 \\
\hline Power tiller & 0.002 \\
\hline Disc plow & 0.002 \\
\hline M B plow & 0.000 \\
\hline Desi hal & 0.007 \\
\hline Disc harrow & 0.267 \\
\hline Leveller & 0.050 \\
\hline Puddler & 0.058 \\
\hline Bundmaker & 0.056 \\
\hline Rotavator & 0.005 \\
\hline Seed cum ferti drill & 0.144 \\
\hline Diesel engine & 0.448 \\
\hline Electric Pump & 0.171 \\
\hline Sprinkler & 0.000 \\
\hline Dripper & 0.000 \\
\hline Spray manual & 0.450 \\
\hline Spray tractor & 0.006 \\
\hline Harvesting worker & 0.986 \\
\hline Harvesting harvester & 0.014 \\
\hline Thresher & 0.427 \\
\hline
\end{tabular}

Figures
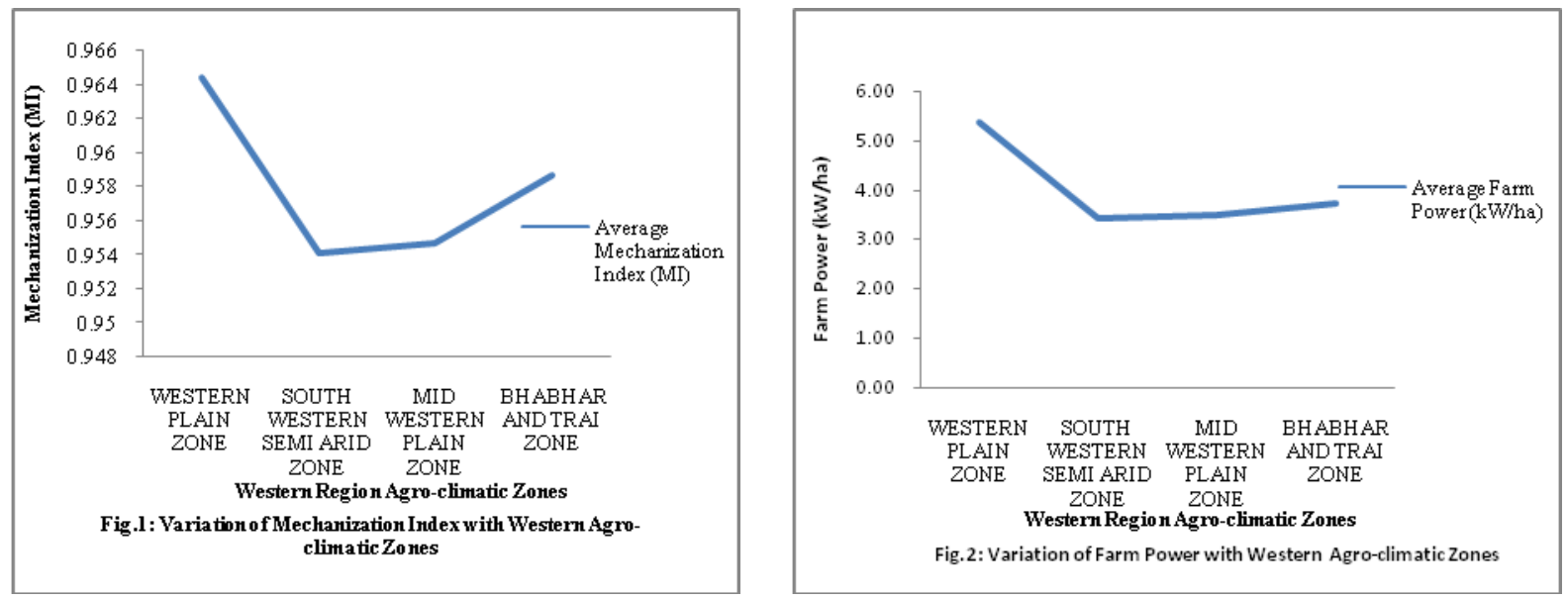

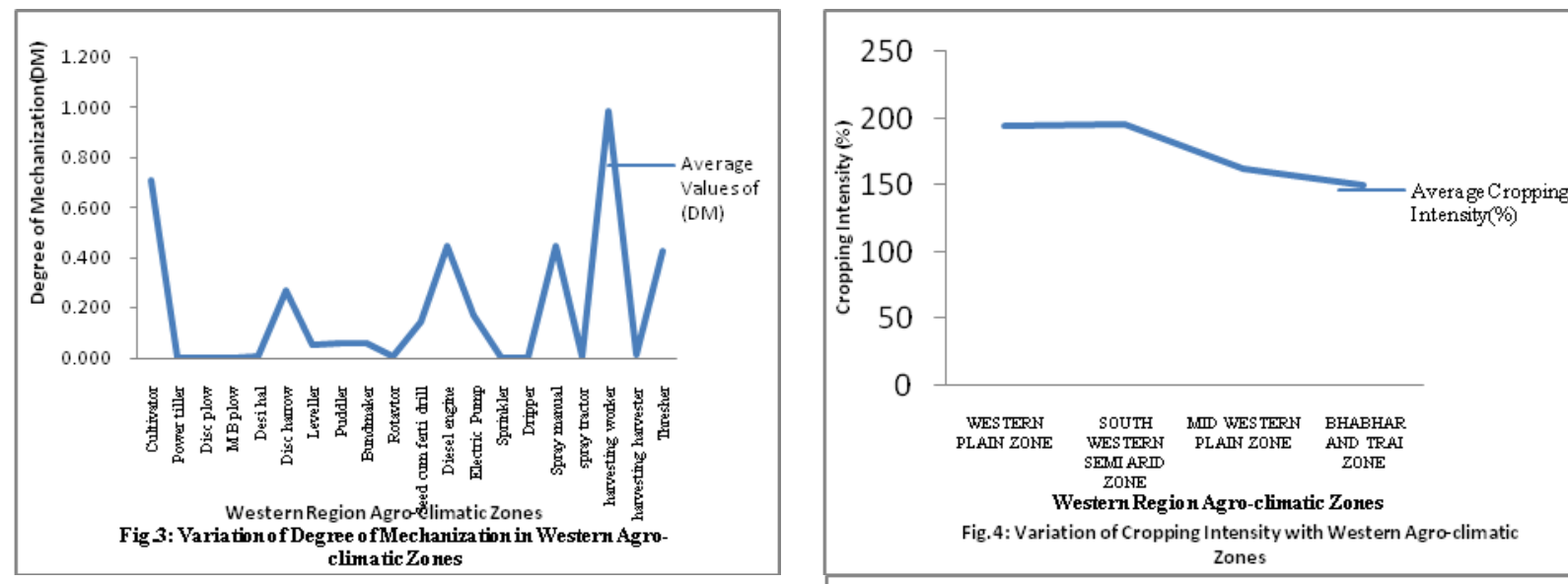
climatic Zones
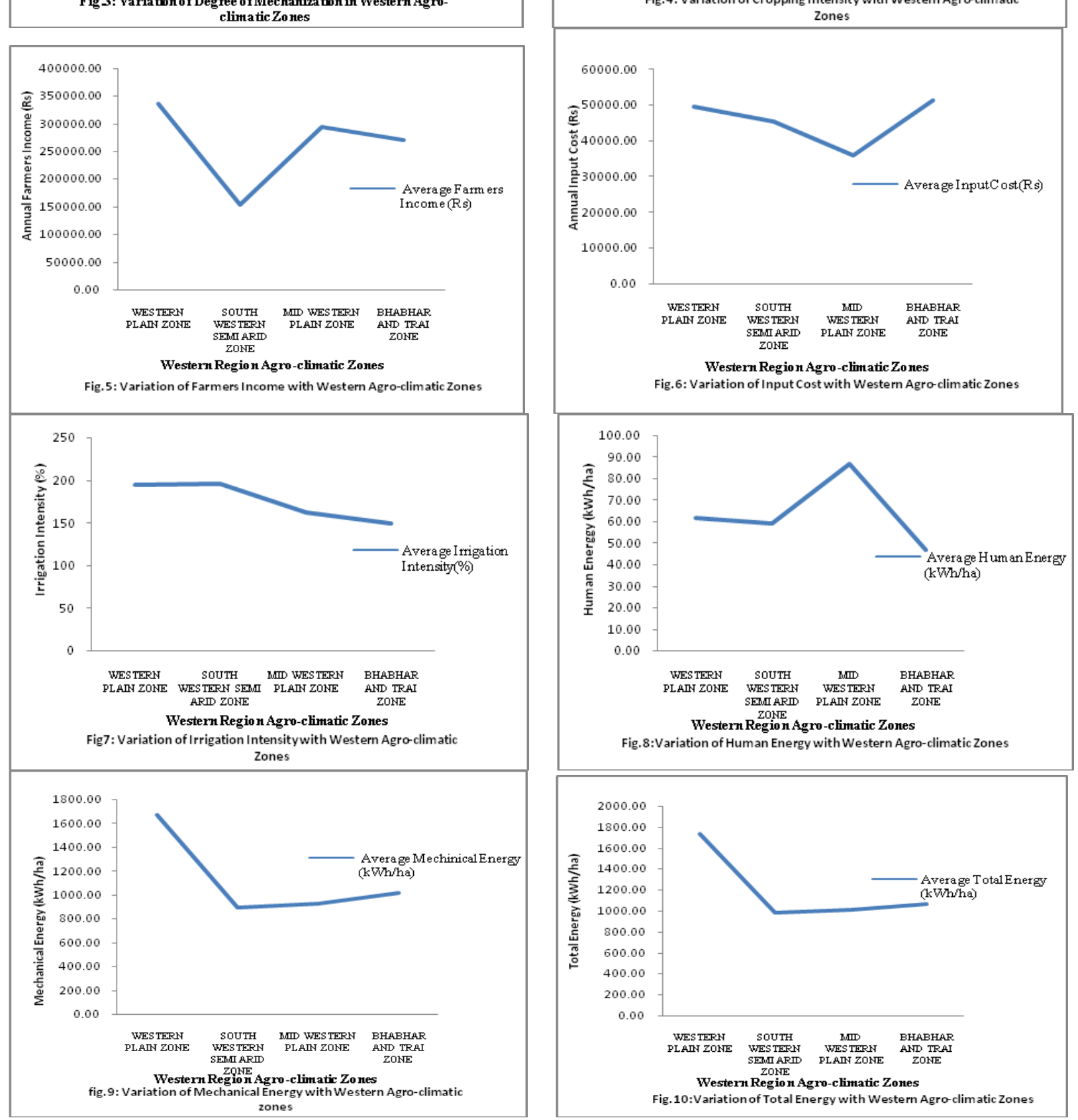
Similarly mechanization indicators and other parameters of western plain zone are also high in compare to other three zones in western region as shown in graphs from 1 to 10 . The degree of mechanization of different farm implements in different unit operation is also shown in table 2. It is also found that the degree of mechanization of harvesting worker is highest than mechanization with cultivator. Still harvesting with harvesting worker is very popular among the farmer and farm implement cultivator is also very versatile farm implement for the farmer.

In conclusion, the mechanization index, power availability, total energy, mechanical energy, are highest in western plain zone in comparison to south western semi arid zone, mid western plain zone and bhabhar and tarai zone i.e. $0.964,5.36 \mathrm{~kW} / \mathrm{ha}, 1738.27 \mathrm{kWh} / \mathrm{ha}$, and $1676.74 \mathrm{kWh} /$ ha respectively but human energy is highest in mid western plain zone i.e. $87.03 \mathrm{kWh} / \mathrm{ha}$ in comparison to other three western zones of western region. The cropping intensity of mid western plain zone district is $196 \%$ which is more than western plain zone as well as other two western zones. The average value of mechanization index, power availability, total energy, mechanical energy, cropping intensity, human energy, annual farmer income, annual input cost, irrigation intensity in western region of Uttar Pradesh are 0.958, $3.98 \mathrm{~kW} / \mathrm{ha}, 1203 \mathrm{kWh} / \mathrm{ha}$, $1132 \mathrm{kWh} / \mathrm{ha}, 176 \%, 63.73 \mathrm{kWh} / \mathrm{ha}$, Rs.263538, Rs. 45609 and $176 \%$ respectively.

\section{References}

Anonymous. 2018. Agriculture Census 201516 (Phase I) Provisional Results, Department of Agriculture, Cooperation and Farmers Welfare, Government of India (GOI). Report of Agriculture census, 2015-16.

Anonymous. 2018. Annual Report 2017-18, Department of Agriculture, Cooperation and Farmers Welfare, Ministry of Agriculture and Farmers Welfare, Government of India, New Delhi, 93 p.

Almasi, M., S. Kiani, and N. Loui-mi. 2000. Principles of Agricultural Mechanization. Ma soumeh (PBUH) Publication. Ghom, Iran. PP. 19-40.

Roy Ramendu and Hasib Ahmad, 2015: State Agricultural Profile of Uttar Pradesh. Report of Agriculture profile 2014-15.

Gifford, R. C., and A. G. Rijik. 1980. Guidelines for Agricultural mechanization strategy in development. Economic and Social Commission for Asia and the Pacific (ESCAP), Regional Network for Agricultural machinery.

Morris, J. 1985. The economics of small farm mechanization. In 'Small Farm Mechanization for Developing Countries' (eds P. Crossley and Kilgour), pp. 171-184, John Wiley and Sons: New York.

Nowacki, T. 1978. Methodology used by ECE Countries in fore-casting mechanization developments. United Nations Economic Commission for Europe, AGRI/ MECH Report No. 74.

Nowacki, T. 1984. Changes and trends in the quantity and balance of energy consumption in agriculture (general methodology). FAO/ ECE/AGRI/MECH Report, No. 105, Geneva p. 36.

Andrade, P. and B. Jenkins (2003). "Identification of Patterns of Farm Equipment Utilization in Two Agricultural Regions of Central and Northern Mexico". Agricultural Engineering International: the CIGR Journal of Scientific Re-search and Development. Invited Overview Paper. Vol. V. June 2003.

Ramirez, A. A., A. Oida, H. Nakashi-ma, J. Miyasaka, and K. Ohdoi. 2007. Mechanization index and machinery energy ratio assessment by means of an 
Artificial Neural Network: A Mexican case study. Agricultural Engineering International. Manuscript PM 07002, 2.

Rijk, A. G. 1989. Agricultural mechanization policy and strategy- the case of Thailand. Asian Productivity Organization, Tokyo, Japan.

Singh, G. and De, D. 1999. Quantification of a mechanization indicator for Indian agriculture. Applied Engineering in Agriculture, 15(3): 197-204.
Singh, G. 2006. Estimation of a mechanization index and its impact on production and economic factors- A case study in India. Bio-systems Engineering, 93(1): 99-106

Zangeneh, M., M. Omid, and A. Akram. 2010. Assessment of agricultural mechanization status of potato production by means of Artificial Neural Network model. Australian Journal of Crop Science, 4(5): 372-377.

\section{How to cite this article:}

Tarun Kumar Maheshwari and Ashok Tripathi. 2019. Determination of Agricultural Mechanization Parameters for Western Region of Uttar Pradesh, India. Int.J.Curr.Microbiol.App.Sci. 8(09): 132-140. doi: https://doi.org/10.20546/ijcmas.2019.809.018 